\title{
Circulating Endothelial Cells as Potential Markers of Atherosclerosis
}

\author{
Yang Gao, Chunyan Liu, Xiangjian Zhang, Jian Gao, Chunyan Yang
}

\begin{abstract}
Background and Purpose: Vascular endothelial cell (VEC) injury represents a major initiating step in the process of atherosclerosis, which may lead to cerebral infarction. "Circulating endothelial cell" (CEC) is an index of ongoing endothelial injury, while intimal-medial thickness (IMT) detected by sounography was used to evaluate the severity of atherosclerosis. However, to our knowledge, there is no study that investigated the relationship of these two determinations. Our study was designed to address correlate CEC with IMT. Methods and Results: The study population consisted of 30 patients with acute cerebral infarction (ACI) and 30 ageand sex-matched volunteers as controls. The CEC counts were determined using Hladovec's method. All subjects underwent a 2dimensional ultrasound examination of both carotid arteries to measure IMT. CEC counts in ACI group were significantly increased compared with control group $(4.88 \pm 2.14$ cells $/ 0.9 \mu \mathrm{l}$ vs $2.73 \pm 1.95 / 0.9 \mu \mathrm{l}, P<0.01)$; IMT in ACI patients was also significantly thicker compared with volunteers $(2.72 \pm 1.07 \mathrm{~mm}$ vs $1.73 \pm 0.99 \mathrm{~mm}, P<0.01)$. There was positive correlation between CEC counts and maximal carotid artery IMT in both groups ( $\mathrm{r}=0.522, P<0.01$ in ACI patients and $r=0.395, P<0.05$ in healthy volunteers). Conclusions: Circulating endothelial cell counts can directly reflect the vascular injury. CEC counts parallel IMT. The CEC may be an independent predictor of cerebral infarction.
\end{abstract}

RÉSUMÉ: Cellules endothéliales circulantes comme marqueurs potentiels de l'athérosclérose. Contexte et objectif : Une lésion des cellules endothéliales vasculaires constitue une étape majeure initiant le processus de l'athérosclérose et pouvant mener à l'infarctus cérébral. La cellule endothéliale circulante (CEC) est un témoin de la lésion endothéliale active alors que l'épaisseur intima-média (ÉIM) évaluée par ultrasonographie a été utilisée pour déterminer la sévérité de l'athérosclérose. Cependant, à notre connaissance, aucune étude n'a examiné la relation entre ces deux mesures. Le but de notre étude était d'analyser la relation entre la CEC et l'ÉIM. Méthodes et résultats : La population étudiée était constituée de 30 patients atteints d'un infarctus cérébral aigu (ICA) et de 30 volontaires appariés pour l'âge et le sexe. Le décompte CEC a été effectué au moyen de la méthode de Hladovec. Tous les sujets ont subi un examen bidimensionnel par ultrasons des deux artères carotides pour mesurer l'ÉIM. Le décompte CEC dans le groupe ICA était significativement plus élevé par rapport à celui du groupe témoin $(4,88 \pm 2,14$ cellules $/ 0,9 \mu \mathrm{L}$ vs $2,73 \pm 1,95 / 0,9 \mu \mathrm{L}, \mathrm{p}<0,01)$; l'ÉIM dans le groupe ICA était également significativement plus épais par rapport aux témoins $(2,72 \pm 1,07 \mathrm{~mm} \mathrm{vs} 1,73 \pm 0,99 \mathrm{~mm}, \mathrm{p}<0,01)$. Le décompte CEC et l'ÉIM maximale de la carotide étaient corrélés positivement dans les deux groupes $(\mathrm{r}=0,522$ et $\mathrm{p}<0,01$ dans le groupe ICA et $\mathrm{r}=$ 0,395 et $\mathrm{p}<0,05$ dans le groupe témoin). Conclusions : Le décompte CEC peut refléter directement la lésion vasculaire. Le décompte CEC et l'ÉIM sont en parallèle. Le CEC peut être un prédicteur indépendant de l'infarctus cérébral.

Can. J. Neurol. Sci. 2008; 35: 638-642

The vascular endothelium is a modulator of a variety of biological systems and plays important structural and functional roles in vascular homeostasis. Normal endothelium is antithrombogenic and yet promotes platelet aggregation and coagulation if injured. Moreover, endothelial damage can cause vasospasm, intimal hyperplasia, and arteriosclerotic acceleration. Endothelial injury is harmful even in the absence of disruption of its monolayer integrity. ${ }^{1}$ However, research in clinical settings has been hindered by the inaccessibility of vascular endothelium in both healthy subjects and patients, owing to the paucity of non invasive methods and specific endothelial markers. Circulating endothelial cells (CEC), released from vascular endothelial cell to peripheral blood, can directly reflect the severity of endothelial damage. Thus far CEC is the only specific direct indicator of vascular injury in vivo. ${ }^{2}$
The structural marker of atherosclerosis is carotid intimalmedial thickness (IMT). B-mode ultrasonography with 7.5-MHz high-resolution allows us to detect IMT sufficiently at segments of the common carotid artery (CCA), internal carotid artery

From the Department of Neurology, The Second Hospital of Hebei Medical University (YG, XZ), Shijiazhuang; The Department of Neurology, The First Hospital of Shi Jia Zhuang City (YG, CL, CY); The Department of Ophthalmology, The Hospital of Hebei Geriatrics (JG), Hebei, China.

Received January 31, 2008. Final Revisions Submitted May 12, 2008 Correspondence to: Xiangjian Zhang, Department of Neurology, The Second Hospital of Hebei Medical University, Shijiazhuang, Hebei, 050000, China. 
(ICA) and carotid bifurcation (CB). The carotid artery intimalmedial thickness (CA-IMT) measured by this device is currently used as a surrogate of atherosclerosis, and it has been documented as a good index for evaluating regression or progression of atherosclerosis in clinical trials. We hypothesized that the number of CECs may predict the degree of atherosclerosis and cerebral infarction. Circulating endothelial cells may also correlate with carotid IMT. We therefore investigated the relationship between CEC and CA-IMT in atherosclerotic patients with acute cerebral infarction (ACI).

\section{SubJeCtS ANd Methods}

\section{Study Population}

Circulating endothelial cells and ultrasound were performed in ACI patients aged from 35 to 75 years admitted to the first hospital of Shi Jia Zhuang city between the period of November 2004 to January 2006. There were 18 men and 12 women. Characteristics of the study group are shown in Table 1. Each case was examined with CT or MRI before admission to exclude hemorrhage; neuro-imaging was repeated 72 hours later after the first assessment to detect infarction. The value of NIH Stroke Scale (NIHSS) ranged from 12-16. The control group comprised 19 men and 11 women ranging in age from 39-74 years with normal CT head scans. Routine physical exam and blood work were done. Subjects with stroke, peripheral arterial disease, liver gently. After centrifuge at $395 \times \mathrm{g}$ for 20 minutes at room temperature, the supernatant was collected. $0.2 \mathrm{ml} 0.1 \%$ adenosine diphosphate (ADP) was added, mixed gently for 10 minutes and centrifuged at $395 \times \mathrm{g}$ for 20 minutes; the collected supernatant was then centrifuged at $1200 \times \mathrm{g}$ for 10 minutes. 0.1 $\mathrm{ml} 0.9 \% \mathrm{NaCl}$ was added to the pellet; after gentle shaking, the suspension was dropped into a counting chamber. The CECs were counted for four times under the microscope and the average was recorded.

\section{Ultrasonography}

Intima-media thickness is defined as the distance between lumen-intima interface and media-adventitia interface of the wall. ${ }^{3,4}$ The definition of IMT of the CCA is not uniform and includes two different pathological changes: a general intima media thickening and a local atherosclerotic plaque formation. ${ }^{5}$ The later definition, atherosclerotic plaque, was used in the present study.

After phlebotomy, the patient was placed on the examination table in a comfortable supine position with the neck resting on a pillow and the face turned away from the examiner. Carotid artery ultrasound was performed with a 5 to $10-\mathrm{MHz}$ linear-array transducer (Agilent SONOS-5500, America). Carotid arteries 'IMT' were measured in the distal segment of the common carotid arteries (CCA, 1 to $2 \mathrm{~cm}$ proximal of the bulb) and the

Table 1: Characteristics of the research group

\begin{tabular}{lcccccc}
\hline $\begin{array}{l}\text { Charac- } \\
\text { teristics }\end{array}$ & $\begin{array}{c}\text { Hyper- } \\
\text { tension }\end{array}$ & diabetes & $\begin{array}{c}\text { hypertension and } \\
\text { hyper-cholesterol }\end{array}$ & $\begin{array}{c}\text { diabetes and } \\
\text { hyper-cholesterol }\end{array}$ & $\begin{array}{c}\text { hypertension and } \\
\text { hyper-cholerol } \\
\text { and diabetes }\end{array}$ & $\begin{array}{c}\text { hypertension } \\
\text { and smoking }\end{array}$ \\
\hline cases & 11 & 5 & 4 & 3 & 2 & 5 \\
\hline
\end{tabular}

disease, renal failure, chronic bronchitis, malignant tumor, dyspepsia, malabsorption or auto-immune disease were excluded. There were no catheterization and percutaneous angioplasty procedures before or during the study. Characteristics of the study groups are listed in Table 2.

\section{CEC Counts}

Circulating endothelial cells counts were conducted with Hladovec's method (Hladovec J, Rossman P. Thromb Res. 1973; 3:665-764). In brief, peripheral blood samples were collected from median cubital vein within 72 hours after admission and then put in test tubes containing $3.8 \%$ sodium citrate, and shaken

\begin{tabular}{|c|c|c|c|}
\hline & \multirow{2}{*}{ age } & \multicolumn{2}{|c|}{ sex } \\
\hline & & male & female \\
\hline research group & $57.8 \pm 11.4$ & 18 & 12 \\
\hline control group & $59.1 \pm 10.5$ & 19 & 11 \\
\hline$P$ & 0.65 & & \\
\hline
\end{tabular}




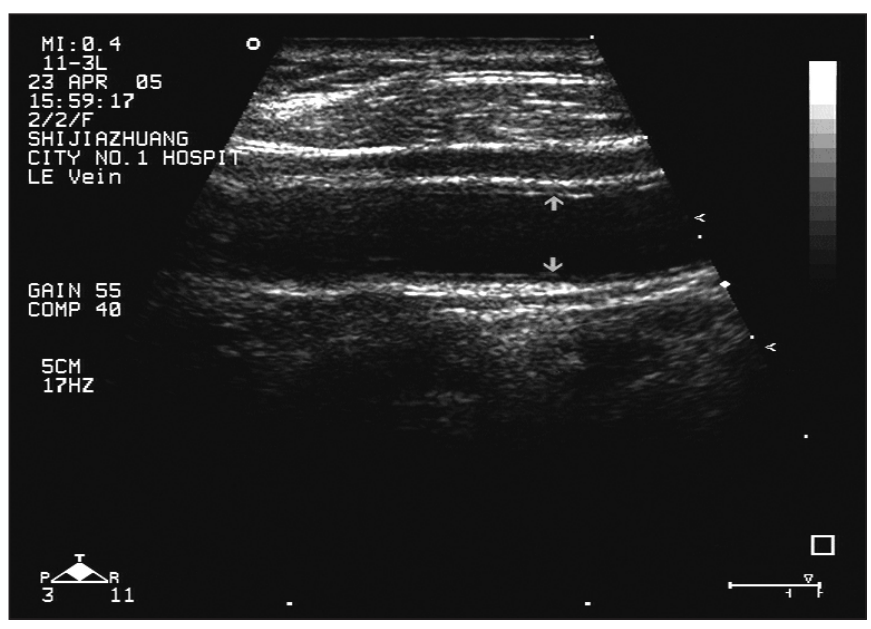

Figure 1: Carotid artery ultrasound: (each arrow showed the lumenintima interface and the distance between the lumen-intima interface to media-adventitia interface represents the IMT)

proximal segment of the internal carotid arteries on both sides. The distance between the two parallel lines (lumen-intima interface to media-adventitia interface) represents the IMT (Figure 1). When an optimal longitudinal image was obtained, it was frozen on the R wave of the ECG, the maximal IMT of CCA, ICA, and CB was recorded.

\section{Statistical Analysis}

All analyses were conducted with SAS 6.12 software. Both $\mathrm{CECs}$ and IMT were expressed as mean $\pm \mathrm{SD}$; the difference between the two groups was analyzed with homogeneity test and Student's $t$-test. Correlation between CECs and IMT was analyzed with linear correlation. The significance level was set at $P<0.05$.

\section{RESULTS}

The clinical details are listed in Table 2 .

\section{CEC Levels}

The CEC counts in ACI patients were significantly higher than those in control group $(4.88 \pm 2.14 / 0.9 \mu \mathrm{l}$ vs $2.73 \pm 1.95 / 0.9$, $P<0.01$, Figure 2).

\section{Carotid ultrasound}

Intimal-medial thickness was significantly increased in ACI patients compared with control group $(2.72 \pm 1.07 \mathrm{~mm}$ vs $1.73 \pm 0.99 \mathrm{~mm}, P<0.01$, Figure 3 ).

\section{Correlation between CECs and IMT}

There was significant positive correlation between IMT and CEC in ACI patients $(r=0.522, P<0.01$, Figure 4$)$ and in control group $(r=0.395, P<0.05$, Figure 5$)$.

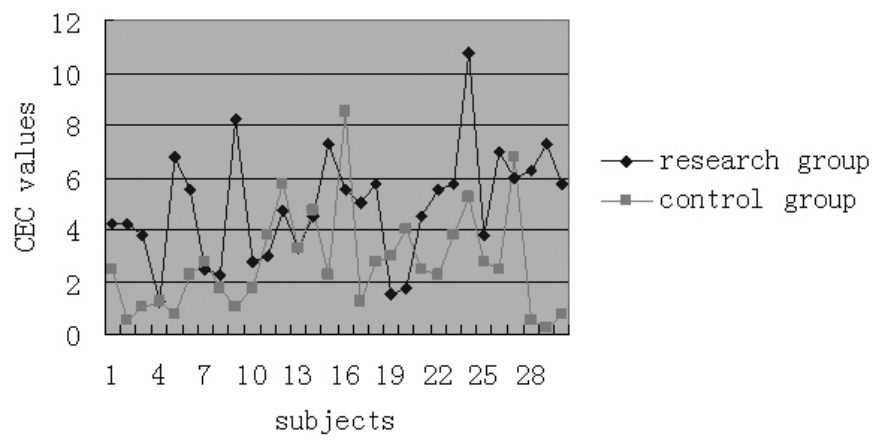

Figure 2: CEC counts (Y-axis change to CEC counts; research group change to ACI Patients, control group change to control).

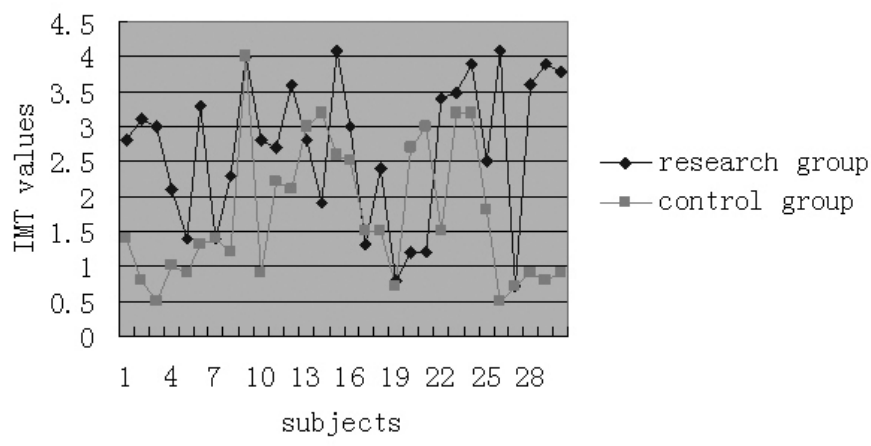

Figure 3: IMT values ( $Y$-axis change to IMT values; research group change to ACI Patients, control group change to control).

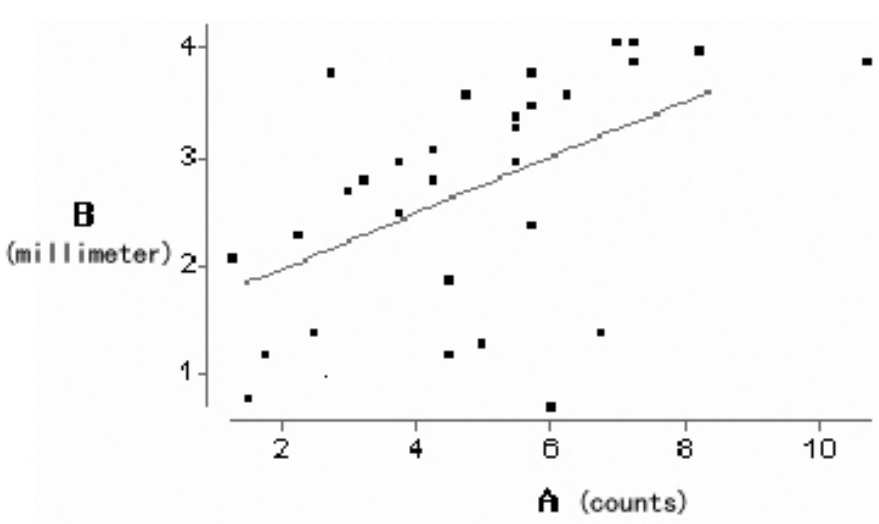

Figure 4: Correlation between IMT and CEC in ACI patients (change $X$ legend to CEC counts, change y-axis legend to IMT values (mm), $r=0.522, P<0.01)$. 


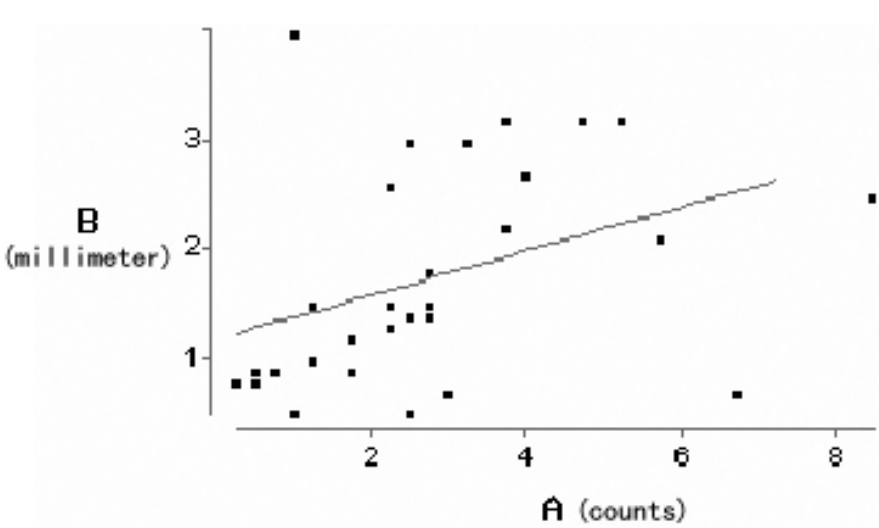

Figure 5: Correlation between IMT and CEC in control group (change $X$ legend to CEC counts, change y-axis legend to IMT values ( $\mathrm{mm}$ ), $r=0.395, P<0.05$ ).

\section{DISCUSSION}

To our knowledge this is the first simultaneous evaluation of CEC and IMT and correlation of these two measures. The CEC counts were found to be increased in ACI patients, as expected IMT values were higher as well in ACI patients; these parallel changes had a significant positive correlation.

Over the last two decades, cumulative evidence has indicated that the vascular endothelium is more than just an anatomical barrier between the bloodstream and the vascular wall. ${ }^{6}$ The single-cell layer of endothelial cells has been recognized as an active paracrine, endocrine and autocrine organ that is indispensable for regulation of vascular tone and maintenance of vascular homeostasis. The vascular endothelium is a complex modulator in a variety of biological systems and, therefore, understanding vascular endothelium may lead to improvements in the treatment of cardiovascular disorders. Normal endothelium has antithrombogenic function; when damaged, it promotes platelet aggregation and coagulation.

Circulating endothelial cells are VECs released to peripheral blood either in physiological or in pathological condition. The increase in CECs indicates endothelial dysfunction or injury. So far, CEC is the only specific direct indicator for vascular damage in vivo. Compared with other indices such as nitric oxide, CEC better reflects vascular injury. ${ }^{7}$

The CEC can be used to track the vascular integrity and, therefore, to infer vascular function. In fact, defects in endothelial structure are hallmarks of vascular diseases, including systemic and pulmonary hypertension, atherosclerosis and restenosis. In normal individuals, the number of CECs is low. The CEC number is positively correlated with the severity of endothelial damage. The VEC injury is considered to be an early and important process in the pathogenesis of atherosclerosis. Mild and persistent VEC injury can result in intimal hyperplasia. ${ }^{8}$ The CEC number has been confirmed to be increased in patients with acute cerebral infarction, ${ }^{9}$ acute myocardial infarction and unstable angina. ${ }^{10-12}$ Our data also demonstrated that in ACI patients, the CEC number was significantly increased compared with healthy volunteers.

The IMT has now been accepted as a validated marker for the process of atherosclerosis. Moreover, IMT also shows a direct correlation with cerebral infarction. It was estimated that each $0.11 \mathrm{~mm}$ increase in IMT is associated with $11 \%$ increase in the risk of infarction. ${ }^{13}$

Sonography is noninvasive and accurate (resolving power is $0.1 \mathrm{~mm}$ ), allowing us to apply it to IMT measurement. Another advantage of sonography is that it is not affected by arterial diameter. In this respect, sonography is even more accurate than arteriography in the early stage of atherosclerosis, as arterial dilation at this stage compensates for the arterial thickening and the arterial lumen diameter is relatively normal. ${ }^{14}$ Sonography may therefore be the most accurate method for assessing the development of atherosclerosis.

Two different pathological terms describe IMT: general intimal media thickening and local atherosclerotic plaque formation. Because the local atherosclerotic plaque usually determines the stenotic status, many studies have used stenotic plaques to evaluate the disease severity, ${ }^{15-17}$ we therefore used local atherosclerotic plaque to determine IMT. Our data showed that IMT was significantly increased in ACI patients compared with the controls group.

In our study, both CEC and IMT were increased in ACI patients. Moreover, there is a positive linear correlation between CEC and IMT in both ACI patients and the controls group, although this correlation in healthy control is not clear. It has been well documented that there is a negative correlation between endothelial function and increased IMT. The higher the $\mathrm{CEC}$, the more severe the carotid atherosclerosis as presented by carotid IMT. These data suggest that in clinical practice, CEC can be used to evaluate endothelial status. A study also indicated that the increased CEC can predict the development of cardiovascular and vascular events. Circulating endothelial cells count is an easy, cheap, accurate and reliable technique; it may be applied as routine exam in suspected cardiovascular diseases. In conclusion, CEC, a vascular injury marker, and IMT, a atherosclerotic index, have a close relationship. Circulating endothelial cells therefore can be used to diagnose atherosclerosis, to evaluate its severity and to follow the therapeutic efficacy of therapies applied to treating or preventing atherosclerosis.

\section{REFERENCES}

1. Segal MS, Bihorae A, Koc M. Circulating edothelial cells: tea leaves for renal disease. Am J Physiol Ren Physiol. 2002; 283(1): F11-19.

2. Takahashi H, Harker LA. Measurement of human endothelial cells in whole blood. Thromb Res. 1983; 31(1): 1-12.

3. Pignoli P, Longo T. Evaluation of atherosclerosis with B-mode ultrasound imaging. J Nucl Med Allied Sci. 1988; 32(3): 166-73.

4. Pignoli P, Tremoli E, Poli A, Oreste P, Paoletti R. Intimal plus medial thickness of the arterial wall: a direct measurement with ultrasound imaging. Circulation. 1986; 74(6): 1399-406.

5. Blankenhorn DH, Rooney JA, Curry PJ. Non-invasive assessment of atherosclerosis. Prog Cardiovasc Dis. 1984; 26(4): 295-307.

6. Gulati R, Lerman A, Simari RD. Therapeutic uses of autologous endothelial cells for vascular disease. Clin Sci. 2005; 109(1): 27-37. 
7. Zilla P, Von Oppell U, Deutsch M. The endothelium: a key to the future. Carddiovasc Surg. 1993; 8(1): 32-60.

8. Vanhoutte PM. Endothelial dysfunction and atherosclerosis. Arch Mal Coeur Vaiss. 1997; 90(6): 9-19.

9. Wu S, Liu S, Zhao R. Effect of longshoudan on serum tumor necrosis factor and circulating endothelial cell levels in acute cerebral infarction patients. Zhongguo Zhong Xi Yi Jie He Za Zhi. 2000; 20(2): 91-3.

10. Rubanyi GM. The role of endothelium in cardiovascular homeostasis and diseases. J Cardiovasc Pharmacol. 1993; 22 Suppl 4: S1-14.

11. Lüscher TF. The endothelium as a target and mediator of cardiovascular disease. Eur J Clin Invest. 1993; 23(11): 670-85.

12. Ross R. The pathogenesis of atherosclerosis: a perspective for the 1990s. Nature. 1993; 362(6423): 801-9.

13. Salonen JT, Salonen R. Ultrasound B-mode imaging in observational studies of atherosclerotic progression. Circulation. 1993; 87Suppl 3: II 56-65.
14. Pignoli P, Tremoli E, Poli. A Intimal plus medial thickness of the arterial wall: a direct measurement with ultrasound imaging. Circulation. 1986; 74(6): 1399-406.

15. Jackson VP, Bendick PJ. Duplex ultrasound screening for carotid atherosclerotic disease in asymptomatic patients. J Ultrasound Med. 1985; 4(8): 411-15.

16. Josse MO, Touboul PJ, Mas JL, Laplane D, Bousser MG. Prevalence of asymptomatic internal carotid artery stenosis. Neuroepidemiology. 1987; 6(3): 150-2.

17. Van Merode T, Hick P, Hocks PG, Reneman RS. Serum HDL/total cholesterol ratio and blood pressure in asymptomatic atherosclerotic lesions of the cervical carotid arteries in men. Stroke. $1985 ; 16(1)$ : $34-8$. 